\title{
INSULIN RESISTANT DIABETES MELLITUS IN ASSOCIATION WITH HAEMOCHROMATOSIS
}

\author{
I. D. Heath, M.B., Ch.B. (Edin.) \\ The General Hospital, Nottingham.
}

\begin{abstract}
INSULIN resistance in association with primary haemochromatosis has been reported on several occasions previously (Allen and Constam, 1929; Root, 1929; Wood and Fitzhugh, 1929; Engel, 1934; Eskind, Franklin and Lowell, 1953; Colwell and Weiger, 1956; Darnaud, Denard, Moreau, Voisin and Pujol, 1958; Uhry, Marcel and Cohen, 1958; Justin-Besancon, Pequignot, Deuil, Etienne, Magdelaine and Jullien, 1960; Michon, Larcan, Hurlet and Vert, 1961). The presence of antibodies to exogenous insulin have been demonstrated in two well documented cases (Eskind, Franklin and Lowell, 1953; Colwell and Weiger, 1956). So far as the author has been able to ascertain, this is the first case in which the "albumin associated" insulin antagonist described by Vallance Owen, Dennes and Campbell (1958) has been estimated. It was present in normal amounts.
\end{abstract}

\section{Case Report}

Mr. F.S., aged 53, having suffered from alopecia totalis since the age of 35, was admitted on 29.11.61 with a four-month history of thirst, polyuria and weight loss (21 lbs. $9.6 \mathrm{~kg}$.). He was mildly ketotic and dehydrated, but no other unusual feature was noted. There was no family history of diabetes. He was stabilised on 72 units of Lente Insulin and a 2,500 calorie diet and discharged. He was readmitted on 4.4.62, in an unstable diabetic state, complaining over the previous month of episodes of intermittent abdominal pain and vomiting associated with constipation.

On Examination the liver was noted to be two fingers' breadth enlarged, firm and smooth, and there was also epigastric tenderness. "Liver nails" were at this time noted. He was not pigmented. There was no obvious cause for the ketosis. Blood sugar was $350 \mathrm{mg}$. $/ 100 \mathrm{ml}$., and his urine contained $2+$ ketones. Dehydration was corrected by intravenous drip, and the vomiting controlled by intramuscular chlorpromazine. The diabetes remained difficult to control and a gradual rise in the insulin requirements occurred, in spite of control of ketosis and the absence of any infection. Finally, 96 units of soluble insulin four-hourly were required to control the ketosis. Hepatomegaly increased and the spleen became palpable.

Investigations. Faecal occult blood examination was persistently positive, but barium meal and enema examination showed no abnormality. $\mathrm{Hb}$. $95 \%$ $(15.1$ g.), WBC 5,000. Liver function tests: alkaline phosphatase 21 K.A. units $/ 100 \mathrm{ml}$., SGPT 200 unitst $\mathrm{ml}$.; electrophoresis of plasma proteins showed slight increase in gamma globulin; serum amylase 200 Somogyi units $/ 100 \mathrm{ml}$. and prothrombin tinge $94 \%$ of normal. Other causes of insulin resistane were sought, and urinary 17-ketogenic and 17 hydroxysteroids were $4.6 \mathrm{mg}$. and $14.1 \mathrm{mg} . / 24 \mathrm{hrs}$. respectively; urinary gonadotrophins were 5 mouse u. $/ 24$ hrs., X-ray of the pituitary fossa was norm\$. At this point, needle biopsy of liver was performen and appearances histologically compatible wim haemochromatosis with mild cirrhosis were found. The serum iron (fasting) on two occasions was 144 and $150 \mu \mathrm{g} . / 100 \mathrm{ml}$. Unsaturated serum iron binding capacity $74 \mu \mathrm{g}$. $/ 100 \mathrm{ml}$. (i.e. the plasma was $63 \%$ saturated). Radio-active iron uptake $55.3 \%$ of i⿱ gested dose. Marrow biopsy showed no excess iren pigment. Serum $B_{12} 244 \mu \mu \mathrm{g} . / \mathrm{ml}$. Skin biopsy she iron pigment deposited in the deeper layers of the corium and in the sweat glands. ECG normalo A sample of plasma was freeze-dried and sent to 45 \% Vallance Owen of Newcastle. Estimation of albumin-associated insulin antagonist showed that?his was present in normal quantities and had normal activity.

Progress. Following administration of $15 \mathrm{~m}$. prednisolone t.d.s., a dramatic fall in insulin requirements occurred within a few days. A more gradư 1 fall in his requirements took place over the nost few weeks. The patient was finally stabilised ofh 72 units of soluble insulin and 120 units of protamige zinc insulin daily.

He was referred to Professor Sherlock at the Rovit Free Hospital, to which he was admitted, and the above finding confirmed. During his stay there, the prednisolone was gradually withdrawn in an attempt to find out whether or not the insu Fin resistance would relapse. Unfortunately this occurred, and prednisolone therapy was recommenced. Weekgy venesections of 1 pint $(580 \mathrm{ml}$.) were also commenced, and have been continued until the present dae, during which time the patient's haemoglobin has remained above $85 \%$ (12 g.) at all times. The serưm iron following the commencement of venesections rose to supernormal levels, although the serum iron binding capacity never became saturated. Over the period to the present date, the prednisolone and the insulin requirements have been reduced until on 7.4.63 prednisolone was finally stopped, his insugn requirements at that time being 56 units of solubbe and 96 units of PZI. The requirements have further fallen until on 30.11 .63 they were 40 units of solufile and 80 units of PZI daily.

\section{Discussion}

Insulin antagonists and insulin resistance haye recently been reviewed, (Berson and Yalow, 1958; 
Vallance Owen, 1960; Field, 1962a and Wright, 1960). From these reviews it is apparent that there are tissue and plasma insulin antagonists. Depending upon the amount of these antagonists present, a state may arise in which more than 200 units of insulin are required daily to control the diabetic state. If this persists for more than 48 hours, insulin resistance is then said to exist (Root, 1929). Antagonism to insulin occurs in certain endocrine abnormalities associated with hyperfunction of adrenal, thyroid or pituitary glands, but these will not be discussed further, as hyperfunction has been excluded in this case by the investigations performed. Similarly, infections, ketoacidosis, and obvious malignancy have been excluded. Tissue antagonists, although still a possible cause of insulin resistance (Field, Johnson and Herring, 1961), are unlikely in view of material to be discussed later. The antagonists which occur in plasma and serum can roughly be divided into two groups, those produced by the body under normal and certain abnormal circumstances, and those requiring exogenous insulin administration for their production. In the former group, various antagonists have been isolated, by electrophoretic analysis of the serum, e.g., the albumin associated fraction (Vallance Owen, Dennes and Campbell, 1958). This fraction occurs normally in diabetic and nondiabetic persons. This fraction was stated to be present in normal amounts (Vallance Owen, personal communication) and consequently does not appear to be associated with insulin resistance in this particular instance. Various other fractions mainly associated with the alpha-1, alpha 2, and beta globulins have been described (see Vallance Owen, 1960). Following the administration of exogenous insulin however, antagonists are produced which have the properties of antibodies to insulin (De Filippis and Iannaccone, 1952; Lowell, 1944), and which bind insulin administered, causing it to move electrophorretically with the gamma globulins in the plasma, (Berson, Yalow, Bauman, Rothschild and Newerly, 1956). There appears to be a rough correlation between the titre of antibody present, and the degree of insulin resistance, (Berson and Yalow, 1959), although this has not always been confirmed (Arquilla and Stavitski, 1956). Similar antibodies have been detected in small amounts in many patients receiving exogenous insulin, who are not in fact insulin resistant, and development of insulin resistance appears to be a quantitative phenomenon (Wright, 1960). Such antibodies have been demonstrated in cases of insulin resistance in association with a large number of totally unrelated conditions in otherwise healthy diabetics, (Field, 1959 and 1962a), and also in non-diabetic, otherwise healthy mental patients, undergoing insulin coma therapy (Banting, Frank and Gairns, 1938). On two occasions they have been described in association with haemochromatosis, (Colwell and Weiger,
1956; Eskind, Franklin and Lowell, 1953). In studying these antibodies Colwell and Weiger (1956) postulated that deposition of iron in the cells of the reticulo-endothelial system might stimulate them to produce this antibody. This appears unlikely since not all sufferers from haemochromatosis develop diabetes, and of those that do, only a small proportion develop insulin resistance (Kleckner, Kark, Baker, Chapman, Kaplan and Moore, 1955; Marble and Bailey, 1951; Sheldon, 1935). If this hypothesis were true, it might be supposed that the most seriously affected subjects would develop the worst resistance, and that repeated venesection would improve this. Reduction in insulin requirements following venesection, has in fact been reported in non-insulin resistant cases of haemochromatosis, (Davis and Arrowsmith, 1953; McAllen, Coghill and Lubran, 1957), and occurred in the present case following the withdrawal of corticosteroids.

In Colwell and Weiger's case the insulin resistance increased in spite of venesection, and in the case of Michon and others (1961) resistance developed seven months after the commencement of venesection, and it was not until ACTH was administered in these two cases that improvement occurred.

Of the remaining eight cases which the author has been able to trace, diagnosis of haemochro- $\varnothing$ matosis was made post-mortem in three, ando was totally unsuspected in this case. Two were females (Darnaud and others, 1958; Uhry, Marcef and Cohen, 1958).

Consequently, in view of these facts and the remarks regarding the infrequency of insulin resistance in primary haemochromatosis quoted above, it appears unlikely that infiltration of the reticulo-endothelial system with iron is responsible for the development of antibodies.

Insulin resistance due to antibodies has been reported in association with hepatic fibrosis resulting from a number of causes (Olsen and Neutzel, 1950). However, the infrequency and haphazard nature of its occurrence in such states makes it appear improbable that hepatic fibrosis per se is a cause of antibody formation. This is also true of other conditions which cause changes in the plasma protein pattern, such as myelomatosis, amyloidosis or nephrotic syndrome (Field, 1962a). The fact that no grossly abnormal gamma globulin band was found may be related to the mildness of the resistance in this case; only 600 units of insulin were required daily to control the ketosis, whereas 11,000 were required by Colwell and Weiger's case, and as stated above there is probably a correlation between the titre of antibody and the degree of resistance.

It therefore appears from a review of work of others, that the insulin resistance which occurs in association with haemochromatosis is in no way directly related to the condition, except that the development of a diabetic state requires 
the administration of exogenous insulin. Insulin resistance is probably no more liable to occur in diabetics with haemochromatosis than in diabetics suffering from idiopathic diabetes, either alone or in association with other disease processes.

The beneficial effects of corticosteroids and ACTH on insulin resistance where high antibody titres are present has been noted previously, (Field, 1962b; Oakley, Field, Sowton, Rigbyand Cunliffe, 1959). The fall in insulin requirements in this particular case was dramatic, occurring within a few days. A similar fall occurred in Colwell and Weiger's case, and in those described by Oakley and others (op. cit.). The mode of action of the corticosteroids is obscure, as the effect occurs before a fall in the antibody titre takes place, although this does occur within 10-14 days of the administration of corticosteroids. As mentioned above, however, not all cases of insulin resistance have high antibody titres, and it has been postulated some mechanism other than simple binding of insulin by the antibody takes place to account for at least some of the resistance. Field, Johnson and Herring (1961) suggest that this may be due to reduce tissue responsiveness. Relapse has been known to occur in many cases treated by corticosteroids (Oakley and others, 1959) and may take up to eighteen months to develop. To the present date, a further relapse has not occurred in this case.

Finally, with regard to the normal serum iron biochemistry, it has recently been shown (Williams, Scheuer and Sherlock, 1963) in a familial study of haemochromatosis, that this condition may be present in a subclinical form for many years before the classical symptoms and signs develop. In these people, similar to the patient described here, the serum iron may be normal and the serum iron binding capacity unsaturated.

\section{Summary and Conclusions}

A case of insulin resistance in association with subclinical haemochromatosis is described. The nature of the resistance is discussed in the light of the work of others, and it is concluded that the two conditions are related only in that the diabetic state requires the administration of exogenous insulin, to which insulin antibodies are formed. The beneficial effects of corticosteroids in this antibody type of insulin resistance are confirmed, and also the fact that repeated venesection may lower the requirements for insulin in a non-resistant diabetic state associated with haemochromatosis. The resistant state is not associated with increased activity of the albumin associated insulin antagonist described by Vallance Owen.

I wish to thank Dr. W. S. Whimster for permission to publish this case. My thanks are also due to Dr. Mprton of Boots Pure Drug Company for freezedrying the plasma, and to Dr. Vallance Owen for performing the estimations of albumin associated insulin antagonists.

\section{REFERENCES}

Allan, F. N., and Constam, G. R. (1929): Insuli Resistance in a Case of Bronzed Diabetes, Med. Clin. N. Amer., 12, 1677.

ArQuilla, E. R., and Stavitski, A. B. (1956): Th Production and Identification of Antibodies to Insulin and their Use in Assaying Insulin, J. clivi Invest., 35, 458.

BANTING, F. G., Frank, W. R., and Gairns, S. (1938) Anti-Insulin Activity of Serum of Insulin Treated Patient, Amer. J. Psychiat., 95, 562.

Berson, S. A., and Yalow, R. S. (1958): Insul Antagonists, Insulin Antibodies and Insulin Resise tance, Amer. J. Med., 25, 155.

Berson, S. A., and YaLow, R. S. (1959): Quantitative Aspects of the Reaction Between Insulin and Insulin-Binding Antibody, J. clin. Invest., 38, 1998

Berson, S. A., Yalow, R. S., Bauman, A., Roth. CHILD, M. A., and NewerLY, K. (1956): Demo stration of 'Insulin-Binding Globulin in the Circulation of Insulin Treated Subjects, J. clin. Invest., 35, 170.

COLWELl, A. R., and WeIGER, R. W. (1956)O Inhibition of Insulin Action by Serum Gammga Globulin, J. Lab. clin. Med., 47, 844.

Darnaud, C., Denard, Y., Moreau, G., Voisin, Ro, and Pujol, M. (1958): Acidose Grave Réduit parr La Cortisone au Cours d'une Hémochromatose Diabète (Le Raincy), 6, 115.

DAVIS, W. D., and ARROWSMITH, W. R. (19537 The Treatment of Haemochromatosis by Massise Venesection, Ann. intern. Med., 39, 723.

DE FILLIPPIS, V., and IANNACCONE, A. (1952): Insuli Neutralising Activity of Gamma Globulins Deraged from the Serum of an Insulin-Resistant Pateref Lancet, $\mathbf{i}, 1192$.

Eancet, 1, 1934). Insulin refraktärer Diabetes schwerm Leberschaden, Klin. Wschr., 13, 1682.

Eskind, I. B., Franklin, W., and Lowell, F. E. (1953): Insulin Resistant Diabetes Mellitus Ass ciated with Haemochromatosis, Ann. intern. Medू, 38, 1295.

FIELD, J. B. (1959): Studies on the Circulating Insulm Inhibitor found in some Diabetic Patients Exhibiting Chromic Insulin Resistance, J. clin. Invest., 38, 53

FIELD, J. B. (1962a): Chromic Insulin Resistance, Metabolism, 11, 636.

FIELD, J. B. (1962b): Studies on Steroid Treatment of Chromic Insulin Resistance, Diabetes, 11, 165.으

Field, J. B., Johnson, P., and Herring, B. (1961). Insulin Resistant Diabetes Associated with Increased Endogenous Plasma Insulin followed by Complefe Remission, J. clin. Invest., 40, 1672.

Justin-Besancon, L., PeQuignot, H., Deuil, M, ETIENNE, J. P., MAGDELAINE, M., and JULLIEN, J. M. (1960): Sem. Hôp. Paris, 36, 2381.

KLECKNER, M. S., KARK, R. M., BAKER, L. A CHAPMAN, A. Z., KAPLAN, E., and MOORE, T. \$. (1955): Ćlinical Features. Pathology and Therapy of Haemochromatosis, J. Amer. med. Ass., 15 g 1471.

LOWELL, F. C. (1944): Immunologic Studies Insulin Resistance II. The Presence of a Neutray lising Factor in the Blood Exhibiting some Characteristics of an Antibody, J. clin. Invest., 23 233.

McAllen, P. M., Coghill, N. F., and Lubran, (1957): The Treatment of Haemochromatosis Quart. J. Med., 26 NS., 251.

MARBLE, A., BAILEY, C. C. (195i): Haemochromatosis, Amer. J. Med., 11, 590. 
Michon, P., Larcan, A., Hurlet, C., and Vert, P. (1961): Hémochromatose et Insulino Resistance. Efficacite d'un Traitment par A.C.T.H., Diabète (Le Raincy), 9, 128.

OAKley, W., Field, J. B., Sowton, G. E., Rigby, B., and Cunliffe, A. C. (1959): Action of Prednisone in Insulin Resistant Diabetes, Brit. med. J., i, 1601.

Olsen, N. S., and Neutzel, J. A. (1950): Resistance to Small Doses of Insulin in Various Clinical Conditions, J. clin. Invest., 29, 862.

Roor, H. F. (1929): Insulin Resistance and Bronze Diabetes, New Engl. J. Med., 201, 201.

SHELDON, J. H. (1935) : 'Haemochromatosis', London : Oxford University Press.

Uhry, P., MARCel, G., and Cohen, A. (1958):
Hémochromatose et Insulino-Résistance, Diabète (Le Raincy), 6, 54.

Vallance OWeN, J. (1960): Insulin Antagonists, Brit. med. Bull., 16, 214.

Vallance Owen, J., Dennes, E., and Campbell, P. N. (1958): Insulin Antagonism in Plasma of Diabetic Patients and Normal Subjects, Lancet, ii, 336.

Williams, R., Scheuer, P. J., and Sherlock, S. (1962): The Inheritance of Idiopathic Haemochromatosis, Quart. J. Med., 31 NS., 249.

Wood, F. C., and FitzhuGH, T. (1929): Haemochromatosis in a Metal Worker. Case Report with Autopsy and a Brief Review of the Literature, Arch. intern. Med., 44, 882.

Wright, P. H. (1960): Insulin Antibodies, Brit. med. Bull., 16, 219.

\title{
PO'TENTIATION OF ANTICOAGULANT THERAPY BY
}

\section{OXYPHENYLBUTAZONE}

\section{(A Probable Case)}

\author{
C. B. HobBs, M.A., M.B. (Cantab), M.C. Path. A. L. Miller, M.B. (Lond.), M.C. Path. \\ J. H. ThorNLeY, M.A., M.B. (Cantab.), D.R.C.O.G. \\ The Courtauld Institute of Biochemistry, The Middlesex Hospital Medical School, W.1.
}

THE DANGERS of giving aspirin or antibiotics to patients on anticoagulant therapy are widely recognised. Aspirin and other salicylates which themselves produce a mild hypoprothrombinaemia are also gastric irritants. Gastrointestinal bleeding may follow the use of these drugs. The possible causes of such bleeding were reviewed by Watson and Pierson (1961). Antibiotic therapy can affect anticoagulant control by interfering with the source of Vitamin $K$ from the intestinal flora and thus indirectly affecting prothrombin production in the liver.

In addition to these there is a growing list of other drugs which potentiate anticoagulant therapy. Attention has recently been drawn to the reduced anticoagulant requirements of certain patients treated with Atromid, a preparation used to reduce serum triglyceride and cholesterol levels (Oliver, Roberts, Hayes, Partridge, Suzman and Bersohn, 1963). A similar effect on anticoagulant therapy was noted by Winters and Soloff (1962) in a patient in whom hypercholesterolaemia was treated with D-thyroxine.

Other drugs reported to potentiate anticoagulant therapy were reviewed by Hellemans (1962) and include dinitrophenol, chlorpromazine, p-amino salicylic acid, testosterone, alcohol and probenecid. Quinine hydrochloride, chloroquine and hydroxychloroquine have also been reported as having an anticoagulant action (Mandel, 1962) and could therefore be expected to exert a synergistic effect on anticoagulant therapy.

Kindermann (1961) reported two cases of spontaneous bleeding after combined therapy with phenindione and phenylbutazone (butazolidin) in the management of superficial thrombophlebitis; and earlier Humble (1953) had reported anomalies in blood clotting in patients on butazolidin. The purpose of this communication is to report a patient on anticoagulant therapy who showed marked prolongation of the prothrombin time and spontaneous bleeding some two weeks after beginning a course of the related compound oxyphenylbutazone (Tanderil).

\section{Case Report}

The patient, a printer, with known rheumatic heart disease and a history of angina for nine years, was aged 50 years when, in May 1960, he was admitted to hospital with a posterior myocardial infarct. He was discharged from hospital to continue on long term anticoagulant therapy with phenindione.

A year later in May 1961 he developed multiple small spontaneous bruises and a small subconjunctival hæmorrhage, during the course of an upper respiratory tract infection with a productive cough. The Quick one-stage prothrombin time was 3.2 times that of the control plasma (therapeutic range 2.0-2.5). Further slight spontaneous bruising occurred in May 